\title{
Rap: a voz da resistência em sala de aula
}

\author{
Rap music: the resistance voice in the classrrom
}

\author{
Valdeci Batista de Melo Oliveira* \\ Universidade Estadual do Oeste do Paraná \\ Cascavel, Paraná, Brasil \\ André Boniatti** \\ Universidade Estadual do Oeste do Paraná \\ Cascavel, Paraná, Brasil
}

\begin{abstract}
Resumo: Este artigo apresenta uma proposta de aplicação didática de letras do rap nacional, para as últimas séries do Ensino Fundamental, inserindo-o na escola, de modo a valorizar esse gênero poético/musical, compreendido, aqui, como forma de expressão e resistência dos segmentos juvenis e jovens da classe social trabalhadora. Essa abordagem didática do rap também se justifica por acreditarmos que o estilo musical traz para o ambiente escolar, ainda no calor da hora, a efetividade das periferias de onde esses grupos provêm. $\mathrm{Na}$ sala de aula, as práticas, os desafios, as lutas, os medos e as esperanças dessa efetividade, plasmada no rap, contêm energias que podem ser força motriz para os alunos problematizá-la questioná-la e ultrapassá-la, quando for possível. Para além da apreciação meramente gustativa o rap pode também proporcionar momentos de debate e de reflexão sobre os espaços de vivências, práticas e valores da vida social e seu entorno. Com a aplicação desta proposta julgamos também poder incentivar a leitura literária e a produção escrita dos alunos e colaborar para que eles encontrem a si mesmos, para além dos estreitos roteiros e estereótipos traçados pelo "establishment", e reciclem seu aparato cognitivo-afetivo, percebendo condições de possiblidades dentro da divisão internacional do trabalho, imposta a países como o Brasil. Para essa discussão, inicialmente são abordados, de forma sucinta, alguns aspectos referentes à escola, à leitura e às contradições existentes nessa instituição secular, com base teórica em Gnerre (1994), Soares (2005), Orlandi (1998) e Zilbermam (1999). Em seguida, destaca a origem do rap, suas peculiaridades e possibilidades de abordagens pedagógicas, tomando como base os estudos de Duarte, Guimarães e Andrade (1999), Fonseca (2011), entre outros. Na sequência, duas letras de rap nacional são analisadas e complementadas com sugestões de encaminhamentos metodológicos, finalizando com algumas considerações sobre o trabalho aqui exposto.
\end{abstract}

Palavras-chave: Rap nacional, educação, interculturalidade e resistência.

\begin{abstract}
This article presents a proposal for the didactic application of national rap music lyrics for the last grades of elementary school, inserting it in the school, in order to value this poetic/musical genre, understood here as a form of expression and resistance of the youth segments and working-class youth. This didactic approach to rap music is also justified because we believe that the musical style brings to the school environment, even in the heat of the hour, the effectiveness of the peripheries from which these groups come. In the classroom, the practices, challenges, struggles, fears, and hopes of this rap-shaped effectiveness contain energies that can be a driving force for students to question and overcome it when possible. . Beyond the mere taste appreciation, rap music can also provide moments of debate and reflection on the spaces of experiences, practices and valuesof social life and its surroundings. With the application of this proposal we also believe that we can encourage students' literary reading and written production and help them to find themselves, beyond the narrow scripts and stereotypes outlined by the establishment, and recycle their cognitive-affective apparatus, realizing conditions of possibilities within the international division of labor, imposed on countries such as Brazil. For this discussion, some aspects concerning school, reading and the
\end{abstract}

*Doutora em Letras, Professora Associada da UNIOESTE. E-mail: valzinha.mello@hotmail.com.

${ }^{* *}$ Estudante de doutorado, mestre em Letras, Professor da rede estadual de ensino do estado do Paraná.

E-mail: zeforis@hotmail.com. 
contradictions existing in this secular institution are initially succinctly approached, based on Gnerre (1994), Soares (2005), Orlandi (1998) and Zilbermam (1999). Then, it highlights the origin of rap, its peculiarities and possibilities of pedagogical approaches, based on the studies of Duarte, Guimarães and Andrade (1999), Fonseca (2011), among others. Following, two national rap music lyrics are analyzed and complemented with suggestions of methodological referrals, ending with some considerations about the work exposed here.

Keywords: National rap. Education. Interculturality and resistance.

\section{INTRODUÇÃO}

Desde o Iluminismo, credita-se à escola o papel de ser um dos instrumentos de emancipação pessoal e coletiva e muitos professores têm se esfalfado no afã de cumprir essa missão, que a cada dia se torna mais complexa, pois o mundo a que chamamos contemporaneidade, inscrito dentro da modernidade líquida ${ }^{1}$ e da simultaneidade temporal, faz com que os sujeitos sejam postos a viver permanente excitação dos excessos de informação, de novidades mercantis, de redes sociais, de mídias. Nesse mundo agitado, a escola como tempo e lugar destinados à formação não tem fôlego para acompanhar as transformações constantes e irrefreáveis das inúmeras esferas da vida social, fazendo com que se agudizem as formas de comportamento e das relações humanas. Alunos que sofrem bullying, alunos violentos, desmotivados, professores doentes e sem energias para enfrentar as demandas de reger uma sala de aula. A escola, como espaço para alunos e professores "viverem e pensarem sua relação como mundo" (CHARTIER, 1994, p.9), por fazer parte do mundo conturbado, foi nele mergulhada, diminuindo cada vez mais o espaço que deveria ser destinado à aquisição do conhecimento, ao pensamento, pois estes demandam tempo e concentração. Essa agitação crescente cada vez consome mais energias que deveriam ser gastas na aprendizagem e formação. Por outro lado, sabemos, também, que a modernidade fez da escola uma instituição que visa o estabelecimento da ordem e a forma(ta)ção física e mental do sujeito (FOUCAULT, 1999). Como se fosse uma fábrica cuja visada fosse a fabricação em série de alunos capazes de atender as demandas do mercado.

Perante essa realidade, se muitos professores adoecem, outros muitos resistem, seja lá por qual mecanismo for, talvez porque ainda dão crédito para as políticas públicas do MEC, ou porque guardam em si mesmos um cadinho de esperança, ou para esforços individuais e de grupos que se propõem a pensar e a resistir a voracidade destes tempos. E esse fenômeno ocorre em todas as etapas da educação formal, da pré-escola aos programas de pós-graduação. Entretanto a face da escola como manufatura insiste em permanecer, as mais das vezes disfarçada, sobretudo pelo modo como são trabalhados os conteúdos e as disciplinas. No caso dos conteúdos da disciplina de língua portuguesa e de literatura, os disfarces conformadores costumam recair na sensaboria do ensino da gramática em si mesma, abstraída da realidade viva do discurso, ou nas escolas literárias e na biografia do autor por si próprios, em lugar das obras, ou na escolha de obras que pouco, ou quase nada, dizem à faixa etária destinada. Apesar disso, sabemos que parte dos alunos faz esforço de tentar tomar posse desses conteúdos, ainda que sua parca

${ }^{1}$ BAUMAN, Z. Modernidade Líquida. Rio de Janeiro: Jorge Zahar, 2001. 
experiência e cerceamento cultural não lhes permite alcançá-los. A grande maioria ainda ter de arcar com a culpa e o ônus dessa não aprendizagem.

As regras da escola como uma estrutura manufatureira priorizam ações e programas criados para cercear, dominar e oprimir, ou seja, forjar sujeitos para heteronomia, em lugar de prepará-los para a autonomia. Grande parte dos desafios pedagógicos atuais a ser enfrentados pela escola decorrem dessa ideologia. Como lidar com conflitos e mentalidades decorrentes da semiformação, via estandardização da cultura, conforme Adorno (1995). Como lidar com o crescente cultivo da violência, canalizado e canonizado no ódio que rumina valores ${ }^{2}$ veiculados pelo status quo. Como lidar com a estagnação do sonho e da esperança que obstrui o futuro dos jovens da classe trabalhadora, em prol do futuro do mercado. Esses mesmos jovens que, desde a gestação foram e continuam sendo maltratados, estigmatizados, reprimidos e esquecidos que, por falta de opções, fazem da escola seu maior espaço público de socialização, no lugar das praças de alimentação, dos shoppings ${ }^{34}$, das praias, dos clubes sociais, das academias, das viagens e outros espaços públicos de convivência social.

Embora no Brasil a parcela do PIB para a Educação tenha crescido muito nos últimos anos, ainda assim ela é ínfima, porque as prioridades do mercado se sobrepõem e não permitem grandes investimentos no futuro dos jovens. Jovens que vivem "a experiência de não encontrar um lugar no mundo que é uma das mais radicais e desesperadas experiências que o homem pode ter" (ARENDT, 1988, p. 527). Na atualidade é recorrente o fenômeno de, em diversos países, os jovens fazerem dos motins uma das poucas formas de visibilidade e saída, quando não fazem do crime, do tráfico ou do jihad a saída encontrada, como estão a fazer muitos jovens franceses ou de outros países, que ouvem o canto de Cila e Caríbdis do ISIS ${ }^{5}$.

Some-se a essas aporias o fato de que as escolas permaneceram as mesmas, desde a época da autoridade inquestionável do professor Aristarco impermeável à realidade dos alunos dentro e fora dos muros escolares do ateneu figurado em romance por Raul Pompeia. Mais de um século nos separam das rudezas do Ateneu (1888), mas muitos de nós professores continuamos impermeáveis aos desafios da sexualidade imposta; às drogas; à violência; ao preconceito (racial, religioso, social e de orientação sexual e de gênero); à prostituição; à gravidez na adolescência; ao descaso e desamor dos familiares e outras formas de opressão vividas pelos jovens que, somente a contrapelo, são

\footnotetext{
2 “Toda cultura, toda classe, todo século constrói seus próprios álibis para a agressão" (Gay, 1995, p. 43).

${ }^{3}$ GALINDO, Rogerio Waldrigues. Tumulto no Palladium faz ressurgir pedidos para que pessoas sejam barradas em shoppings. Jornal Gazeta do Povo. Disponível em: http://www.gazetadopovo.com.br/blogs/caixa-zero/tumulto-no-palladium-faz-ressurgir-pedidos-paraque-pessoas-sejam-barradas-em-shoppings/. Acesso em: $05 \quad$ jan. 2016. http://www.gazetadopovo.com.br/blogs/caixa-zero/apos-tumultos-liminar-permite-que-shoppingpalladium-barre-jovens/

${ }^{4}$ GALINDO, Rogerio Waldrigues. Após tumultos, liminar permite que shopping Palladium barre jovens. Jornal Gazeta do Povo. Disponível em: http://www.gazetadopovo.com.br/blogs/caixa-zero/apostumultos-liminar-permite-que-shopping-palladium-barre-jovens/. Acesso em: 05 jan.2016.

${ }^{5}$ http://ccaa.elpais.com/ccaa/2012/02/20/valencia/1329764951_838007.html - Consulta em 10 de maio de 2015 http://www.bastamag.net/L-augmentation-des-emeutes-un - Acesso em 12 de janeiro de 2016.
} 
tomados como objeto de reflexão em sala de aula. E, quando o são, essas reflexões costumam ser norteadas pela visão excludente do moralismo pequeno burguês. Esse "silêncio institucional" demanda dos jovens buscar soluções próprias para encontrar seu nicho sociocultural, enfrentar a realidade, debatê-la, questioná-la e denunciá-la. O rap, embora já seja uma mercadoria, ainda tem potência para trazer estas questões à baila e problematizá-las, sem se recobrir do verniz censor do status quo.

Dentro e fora da escola, esse é o contexto em que vivem tais jovens, principalmente os oriundos das periferias das grandes cidades, périplo da violência institucionalizada. Para Arendt, a institucionalização da violência "indica o quanto a violência e sua arbitrariedade foram consideradas corriqueiras e, portanto, desconsideradas; ninguém questiona ou examina o que é óbvio para todos (Idem, p. 16). Ao cabo resta a esses jovens fazerem do rap uma poética porta-voz de suas inquietações, críticas e denúncias, numa busca de (re)construção de sua identidade, iniciativa pouco valorizada pela escola. Contudo, "não se pode mais conceber um currículo escolar que não considere de modo radical a diversidade presente em nossa sociedade (FONSECA, 2011, p. 27).

Para defender a aplicação didática de letras do rap nacional nas séries finais do Ensino Fundamental, com vistas a valorizá-lo, por meio da sua inserção na escola, este artigo traz, inicialmente, algumas considerações importantes, embora sucintas, sobre a relação contraditória entre leitura, escola e literatura. A parte seguinte apresenta argumentos sobre a pertinência de se utilizar letras do rap nacional como suporte pedagógico e as inúmeras possibilidades didáticas que tal gênero poético/musical possibilita, principalmente para que o aluno discuta e vivencie a interculturalidade ${ }^{6}$. Finalizando, duas letras de rap nacional são analisadas sob o enfoque didático que é defendido neste artigo, seguidas de considerações sobre essas possibilidades.

\section{LEITURA, LITERATURA E ESCOLA: UM BREVE DEBATE}

Aos alunos das classes populares, que são a maioria de nossas escolas, é imposto que se apropriem da leitura e da escrita, mas não como sujeitos interpelados pela ideologia e atravessados pelos inconscientes, e sim como sujeitos do desejo aprisionados em uma formação discursiva opressora, que inviabiliza a passagem e entrada em outras formações discursivas, deixando-os, apenas, delas vislumbrar contornos opacos. Nesse sentido, as atividades de leitura e a de escrita são postas para minimizar os aspectos mais visíveis da pobreza e da necessidade de emprego. Esse é o dilema presenciado diariamente na escola pública: "Enquanto lê livros da burguesia, três quartos da

${ }^{6} \mathrm{O}$ termo interculturalidade, segundo Fleuri (2005) refere-se a "um complexo campo de debate entre as variadas concepções e propostas que enfrentam a questão da relação entre processos identitários socioculturais diferentes, focalizando especificamente a possibilidade de respeitar as diferenças e de integrá-las em uma unidade que não as anule". Optamos por esse termo, em detrimento aos termos multiculturalidade e transculturalidade por abarcar a necessária relação de respeito entre os "diferentes" que ora pretendemos. Sobre isso, consultar CANDAU, V. M. Diferenças culturais, interculturalidade e educação em direitos humanos. In: Educação e Sociedade, vol. 33, 2012. 
humanidade está impedida de falar, está destituída de seu próprio discurso" (ZILBERMAN, 1982, p.79).

Gnerre (1994, p. 45) afirma que "a começar do nível mais elementar de relações com o poder, a linguagem constitui o arame farpado mais poderoso de acesso ao poder", o que nos leva a refletir sobre as relações implícitas entre linguagem oral e a linguagem escrita e a imposição de superioridade e poder desta sobre aquela.

Orlandi $(1998$, p. 93) também chama à atenção para essa contradição. "As classes populares estão na escola. No entanto, o direito que elas têm é o de aprender as formas legítimas da cultura dominante". E salienta: "é preciso se criar condições para que as classes populares elaborem sua história de leituras que a classe dominante desconhece, ou melhor, não reconhece".

A abordagem de leitura proposta por Freire (1988) também se encaminha para o exercício de um papel social e crítico, pois defende que a leitura pode se configurar em um instrumento para conduzir o leitor ao conhecimento da dominação exercida pela classe dominante, resultando numa compreensão crítica do mundo, corroborando na luta pela igualdade social. Contudo, segundo ele, esta expansão afetivo-cognitiva não será atingida com uma educação "domesticadora", manufatureira e tradicional, pois, "seria uma atitude ingênua esperar que as classes dominantes desenvolvessem uma forma de educação que proporcionasse às classes dominadas perceber as injustiças sociais de maneira crítica" (FREIRE, 1984, p. 89).

E, é nesse espaço de contradição que concepções de práticas pedagógicas que, segundo Magda Soares (2005, p.28), "germina a transformação social", pois, "a leitura é, fundamentalmente, processo político". E todos os envolvidos nesse processo "têm de ter consciência da força de reprodução e de contradição presente nas condições sociais da leitura, e com isso apossar-se desta última como possibilidade de conscientização e questionamento".

Ao abordar a questão do ensino, Barthes (2007) propõe um discurso sem imposições. Para ele, também professor no Colégio da França, "o que pode ser opressivo num ensino não é finalmente o saber ou a cultura que ele veicula, são as formas discursivas através das quais ele é proposto" (BARTHES, 2007, p. 41).

Em outras palavras, as formas discursivas da escola adequadas precisam ser arejadas para poder falar de etnia, gênero, preconceito, diferenças sociais, violência e diversidade sexual e o rap faz isso sem a mínima cerimônia. No rap a palavra é lançada como forma de resistência assim como em outros textos ou outras produções culturais em que o lugar de enunciação seja, por si só, o de um iconoclasta que quebra paradigmas - sociais, culturais e discursivos - parece-nos poder ser uma prática pedagógica libertadora. Daí a opção de fazer abordagens pedagógicas do rap como forma popular de expressão e resistência dos segmentos adolescentes e jovens da classe social trabalhadora, considerando formar leitores capazes de compreender e questionar o leem e o que ouvem. 


\section{RAP: UMA FORMA DE RESISTÊNCIA}

O termo rap é formado pelas letras iniciais de rhythm and poetry - ritmo e poesia. Nascido na periferia das grandes cidades, é muito apreciado pela juventude contemporânea e tem sido visto como expressão genuína dessa parcela da população, atualmente. Essa expressão musical é compreendida, juntamente com o grafite e o break, como um movimento - movimento hip hop . Contudo, neste artigo, será dada atenção ao rap unicamente.

O rap surgiu por volta de 1960, quando apareceram os sistemas de som, que eram colocados nas ruas dos guetos jamaicanos para animar bailes. Os MC's - mestres de cerimônia - comentavam, ao microfone, assuntos pertinentes à sua comunidade, como a violência, a situação política do país e as drogas.

Na década de 1970, muitos jovens jamaicanos foram obrigados a emigrar para os Estados Unidos, pois seu país enfrentava forte crise e levaram consigo o estilo musical. Kool Herc e Afrika Bambaata, ambos jamaicanos, são considerados os precursores do movimento hip hop nos guetos nova-iorquinos, principalmente no Bronx. Dali o movimento propagou-se por muitos países, chegando ao Brasil por volta de 1980.

No Brasil, inicialmente em São Paulo, reveste-se de características próprias, embora nessa fase a influência norte-americana ainda fosse muito acentuada. Na década de 1990, ocorre a eclosão do movimento, com Thaíde e DJ Hum, Racionais MC's, MC Jack, Código 13 e Credo como principais expressões. As letras dessa época são marcadas pelo tom agressivo, é a fase da autoafirmação do rap como estilo musical; os temas giram em torno da negritude e da difusão do movimento.

Atualmente, o rap tem sido entendido como uma forma de expressão musical do jovem da periferia, uma música de contestação que expressa a reivindicação de grande parte da sociedade com dificuldade de acesso ao emprego e ao consumo, buscando a definição de seus territórios e seu pertencimento à sociedade. Pode ser visto como um grito de resistência dos jovens que solicitam perspectivas para seu futuro, em meio ao esvaziamento de sentido contemporâneo e de condições de vida digna, impostos pela sociedade de mercado.

Resistência, segundo Bosi (1996, p. 11) "é um conceito originariamente ético, e não estético. $\mathrm{O}$ seu sentido mais profundo apela para a força da vontade que resiste a outra força, exterior ao sujeito. Resistir é opor a força própria à força alheia".

Com efeito, o rap opõe a força própria à força alheia. A força própria entende-se seu ritmo dialogal, seu discurso ácido e direto, seu lugar de enunciação, sua justa e merecida reivindicação de direitos historicamente negados, reivindicação que agora não quer mais "ninar os da casa grande" (EVARISTO, 2007, p. 21), pelo contrário, quer "incomodá-los em seus sonos injustos". À força alheia compreende-se o discurso hegemônico, arquitetado para silenciar qualquer levante ou insubmissão das chamadas "minorias".

E, como defende Bosi em sua teoria sobre Narrativa e Resistência (1996), aqui aplicada também ao rap, essa oposição/resistência se dá de duas maneiras: como tema e como processo inerente à escrita. 
Deve-se aprofundar o campo de visão. E detectar em certas obras, escritas independentemente de qualquer cultura política militante, uma tensão interna que as faz resistentes, enquanto escrita, e não só, ou não principalmente enquanto tema [...]. A escrita resistente (aquela opção que escolherá afinal temas, situações, personagens) decorre de um a priori ético, um sentimento do bem e do mal, uma intuição do verdadeiro e do falso, que já se pôs em tensão com o estilo e a mentalidade dominantes (BOSI, 1996, p. 22).

E essas duas formas de resistência defendidas por Bosi (1996) - o tema e os processos inerentes à escrita - são identificáveis na maioria das letras do rap nacional. Os temas demonstram resistência porque criticam, denunciam, fazem refletir sobre as reivindicações dos direitos das minorias, dos seus conflitos diários de exclusão e preconceito, da violência na periferia, das dificuldades de acesso aos bens culturais e econômicos; e os processos referentes à escrita mostram resistência ao trazer à tona por meio da voz do rapper _ a fala/dialeto das periferias da grande cidade: informal, estigmatizada por aqueles que defendem como única variedade linguística aceitável a linguagem de prestígio, a norma culta, própria da elite.

Stella Maris Bortoni-Ricardo (2005, p. 23) assinala que a força padronizadora da língua padrão é representada por um vetor que ela denomina de assimilação. Contudo, assinala que as variedades linguísticas de "certas minorias sociais e étnicas nas comunidades urbanas são marcadas por alguns traços que atuam como uma peça de resistência à assimilação" e que "os falantes usam esses recursos de variação da língua para enfatizar sua identidade”. É o que se percebe na variedade linguística utilizada nas letras de rap. Certas escolhas lexicais, de concordância e de estilo dos rappers enfatizam o lugar de enunciação e com isso fortalecem sua identidade e seu pertencimento ao grupo.

O sentimento de etnicidade, a ética da solidariedade como estratégia de sobrevivência, a coesão de grupo e a consequente resistência consciente aos valores da cultura dominante são fatores que justificam os traços não-padrão como marcadores de registro de identidade nas letras de rap. $\mathrm{E}$ isso acontece também com os rappers de maior escolaridade e/ou conhecimento e acesso à variedade formal da língua.

Segundo Bakhtin (2003, p. 113), “a situação social mais imediata e o meio social mais amplo determinam completamente e, por assim dizer, a partir de seu próprio interior, a estrutura da enunciação". Portanto, se pensarmos nas letras do rap nacional, constataremos que a situação social e as vozes que nelas coexistem realmente determinam o modo de enunciação. No rap, “o discurso [...] é também, e, sobretudo, um produtor da cena” (DIAS, 1995, p. 70).

O querer-dizer do rapper poderia ser outro se a sua relação com o meio fosse outra e se seus interlocutores fossem diferentes, pois "toda palavra comporta duas faces. Ela é determinada tanto pelo fato de que procede de alguém, como pelo fato de que se dirige para alguém", e, acima de tudo, "a palavra é o fenômeno ideológico por excelência" (BAKHTIN, 2003).

O microfone tomado como arma e a palavra como munição são metáforas muito 
presentes nas letras de rap. Os versos de Mó H: “minha arma é o microfone, agora eu vou guerrear", mostram que os rappers não abrem mão de sua linguagem, resistem às imposições sociais, conscientes do poder da palavra que tomam para si, "do verbo cru" e do espaço de enunciação que forjam a cada nova produção:

Enquanto o mundo muda pela música/ Preparo poesia de aço na minha siderúrgica/ Um hábito noturno inspirado em Saturno/ E seus anéis em torno, não há retorno/ Eu sempre estive aqui, no verbo cru que nem sashimi/ A verdade virá à tona/ pelo parto, infarto no miocárdio/ Revolução não será televisionada nem virá pelo rádio (BLACK ALIEN, 2004, p. 3).

Nos versos do grupo Racionais MC's (1997) também aparece o uso das metáforas para definir o próprio estilo e a força que a palavra pode assumir. $O$ "assalto metafórico", forte e contundente que pretende aniquilar ideias contrárias e "sabotar seu raciocínio [...] abalar seu sistema nervoso e sanguíneo":

O preto aqui não tem dó/ é 100\% veneno/ A primeira faz bum, a segunda faz tá/ Eu tenho uma missão e não vou parar/ Meu estilo é pesado e faz tremer o chão/ Minha palavra vale um tiro e eu tenho muita munição. / Na queda ou na ascensão minha atitude vai além/ Eu tenho uma missão e não vou falhar/ Meu estilo é pesado e faz tremer o chão/ Minha palavra vale um tiro... eu tenho muita munição/ Na queda ou na ascensão, minha atitude vai além (RACIONAIS MC's, 1997 - grifos nossos).

Trata-se, acima de tudo, de abandonar os padrões alheios, que nada dizem de sua história, e tomar "para si" o direito da palavra, forjar a própria literatura, numa linguagem que lhe é própria. Nesse contexto, a língua tem papel essencial, pois, segundo Bakhtin ela age "como expressão das relações e lutas sociais, veiculando e sofrendo o efeito dessa luta, servindo ao mesmo tempo, de instrumento e de material" (1992, p. 18).

Numa visão freireana, o rapper faz uma leitura do mundo a partir de sua realidade, mas atinge a universalidade; seus problemas e conflitos são de toda uma coletividade, daí o forte caráter dialógico das letras.

Todavia, como já foi mencionado, o rap não é valorizado/analisado na sala de aula, pelo contrário, é visto como música "marginal", devido a sua origem fora do contexto considerado "oficial" pela cultura hegemônica. Disso resulta a quase total inexistência desse gênero nos livros didáticos adotados pelas escolas públicas ou particulares do país todo.

Rojo (2009, p.115) defende que a escola deve potencializar o debate intercultural, "trazendo para dentro de seus muros não somente a cultura valorizada, dominante, canônica, mas também as culturas locais e populares e a cultura de massa, para torná-las vozes de um diálogo, objeto de estudo e de crítica". Nesse sentido, o rap tem muito a contribuir na formação do aluno e ganha importância por ser um movimento gestado entre os jovens. Segundo Duarte (1999, p.18), "fugindo dos modelos externos, fugindo do circuito massificador dos meios de comunicação, ele consegue resgatar, de forma 
muito significativa, as questões sociais geradoras de exclusão”. É uma forma de educação popular, através do uso do ritmo e da palavra:

[O rap] discute, questiona, denuncia. Enfim, retoma uma das funções que a Literatura tem nas sociedades letradas, e o faz sem demarcar espaços de separação entre produtor "autorizado" do texto literário e o consumidor deste. Em outras palavras, o rapper torna-se o literato, no exato sentido da palavra, conquistando o direito de exprimir pela palavra (DUARTE, 1999, p.19).

A valorização da experiência de vida é um dos aspectos legitimadores dos rappers e das letras que compõem. Ter passado por processos de exclusão relacionados à etnia ou à classe social garante-lhes a legitimidade artística, a valorização do seu pertencimento e proporciona matéria prima para suas composições musicais. No rap a mensagem é sempre pessoal, imersa na localidade, em geral, a periferia, mas ao mesmo tempo, universal. "A mesma experiência individual que é relegada a segundo plano nos bancos escolares transforma-se em tema de reflexão e construção da narrativa poética" (SILVA, 1999, p.31).

Para Andrade (1999), o rap garante o fortalecimento da identidade étnica de seus produtores, e cultivá-lo "é investir na sua auto-estima, pois o rap é uma música de origem negra, o que não significa que o conteúdo da música deva ser unicamente nessa temática; o ritmo de estilo musical por si só expressa sua origem" (ANDRADE, 1999, p.90).

Contier (2005) corrobora o fato de que o rap tem um papel social, salientando que o viés da denúncia é marcante, pois "caracteriza-se pela reinvenção do cotidiano através da oralidade de pessoas comuns que denunciam em suas canções problemas graves vivenciados nas situações sociais extremamente adversas".

O rap é compreendido como uma forma de narrativa contemporânea nos estudos de Silva (2006). "Salvando a palavra e resgatando o poder da fala, no sentido benjaminiano, os rappers contam, falam, tanto as suas experiências cotidianas quanto as dos outros" (SILVA, 2006, p.87). Os rappers são os "griots" contemporâneos, segundo o autor. Não são velhos, mas jovens e adolescentes, negros, de classe pobre que "constroem suas mensagens a partir das representações que têm do seu lócus e as comunicam por meio de ritmo e poesia", alertando, aconselhando e "educando" a juventude socialmente excluída através da "poética da exclusão".

Ao defender a utilização didática do rap nacional e sua inserção no currículo escolar no Ensino Médio na área de Linguagens, Códigos e suas Tecnologias, Fonseca (2011), questiona os argumentos de que as letras do rap fazem apologia à violência e às drogas e que tenham linguagem pobre, chula.

Para demonstrar seu ponto de vista, analisa um corpus composto de várias letras de rap nacional e comprova que tais apologias não ocorrem, muito pelo contrário, a maioria das letras traz questionamentos e críticas à "justiça social" da suposta "democracia racial" em que vivemos, buscam a conscientização dos jovens quanto à identidade cultural e às drogas e também analisam as causas e efeitos da violência urbana. Tudo isso, muitas vezes de forma contundente, numa linguagem com forte 
influência da oralidade e/ou desobediência às regras de concordância verbo-nominal, mesmo assim com riqueza poética e rítmica.

A resistência dos professores quanto à utilização de letras de rap em sala de aula se deve, em grande parte, ao desconhecimento ou menosprezo do seu contexto de produção, de sua origem e seus objetivos, da "riqueza das rimas pobres", dos efeitos de sentido, das figuras de linguagem utilizadas. Os casos de falta de concordância verbal são marcas da oralidade, característica muito forte no gênero, o que, de forma alguma desmerece o conteúdo das letras, conforme enfatiza Fonseca (2011).

Deve-se pontuar, contudo, que há um segmento do rap, chamado de gangsta, em que se percebe um estilo mais contundente e agressivo. É desse segmento as letras mais apologéticas no que se refere às drogas e à violência. Este segmento, porém, não será foco das nossas discussões, visto que nosso interesse é justamente o contrário

Ainda segundo Fonseca (2011, p. 33) "o rap nacional pode, em sala de aula, promover, não apenas alguma catarse pela possibilidade de privilegiar identidades negadas, silenciadas na escola, mas também a politização dessas mesmas identidades”, além de dialogar com obras consideradas canônicas e, assim, incentivar a leitura delas:

As letras, além de poderem dialogar com obras literárias consideradas canônicas, mobilizando o aluno para temas nelas contemplados, contribuiriam no questionamento acerca do papel de dados mecanismos poéticos e estilísticos na construção de tais obras. [...] Há, sobremaneira, o indicativo de que o rap mobilizaria os alunos para lerem outros textos [...]. Os mecanismos poéticos, de linguagem, presentes no rap podem, igualmente, servir para que o aluno desenvolva noções de interpretação de textos escritos e orais, e possivelmente contribua com a produção de textos (FONSECA, 2011, p. 34-35).

Acreditando na capacidade formadora da escola e na força do rap - dentro e fora da escola - como forma de resistência, reflexão, crítica, e pela possibilidade de diálogo com outras obras do cânone literário é que se propõem as alternativas pedagógicas a seguir.

\section{UMA PROPOSTA EM SALA DE AULA}

Em seus estudos, Fonseca (2011) delimitou três fases distintas no rap nacional: a primeira caracteriza-se pela autoafirmação da negritude e difusão inicial do movimento hip-hop no Brasil, nos anos 1980; a segunda, já mais solidificada, dá prioridade às denúncias sociais e é responsável pela consolidação identitária do rap, nos anos 1990, e a terceira fase, dos anos 2000 em diante, é marcada pela ironia poética e pela diversificação temática e musical. Deve-se levar em conta que os períodos que marcam cada fase não são estanques e um artista pode apresentar elementos comuns em mais de uma fase, simultaneamente.

Duas letras do rap nacional, de duas fases distintas - a segunda e a terceira - são sugeridas como opção de trabalho em sala de aula do $9^{\circ}$ ano do Ensino Fundamental: A 
cor que falta na Bandeira Brasileira (2002), do grupo Z'África Brasil, da segunda fase, e Melô da propaganda do Grupo Quinto Andar (2005), da terceira fase.

A cor que falta na Bandeira Brasileira (2002), do álbum Antigamente quilombo, hoje periferia, traz características que a definem como pertencente à segunda fase, considerada a fase mais longa do rap nacional. Nessa fase, a exemplo da música aqui destacada, as composições trazem à tona questões embaraçosas da história do Brasil, o preconceito, injustiças sociais, violência urbana, má distribuição de renda, baixa escolaridade e outros temas igualmente importantes. Possibilita um debate intercultural em sala de aula, uma vez que aborda a situação do indígena e do negro no decorrer da nossa História.

O grupo Z'África Brasil foi criado em 1995. O nome do grupo é bem sugestivo: A letra " $Z$ " inicial faz alusão a Zumbi, herói dos Palmares, referenciado em muitas letras dessa fase, num resgate da antiga luta pela liberdade e pela luta atual contra o preconceito.

A música relembra os quinhentos anos de história sangrenta do Brasil: o vermelho do sangue, conforme diz a letra, é a cor que falta à bandeira de um país que dizimou sua população indígena e promoveu a exploração da força de trabalho e a segregação da população negra. Questiona e problematiza a "'ordem e progresso" do país de forma incisiva. $\mathrm{E}$ ao fazer clara intertextualidade com o hino nacional brasileiro como símbolo da nossa nação também o questiona e propõe indiretamente uma releitura deles (da bandeira e do hino como "símbolos nacionais"), para, então, realmente, representarem o Brasil:

E ali estava ela, hasteada/ para que todos pudessem ver as suas cores gradientes/ Simbolizando ordem e progresso/ E aos redores grandes quilombos periféricos/ Um lugar de guerreiros, cujo olhar vermelho/ É pela liberdade entre terras e mares/ Oh, pátria amada e idolatrada, salves e salve [...] Verde, amarelo, azul, branca e vermelha/ São as cores que compõe a bandeira brasileira/ Só que o vermelho não quiseram botar/ É cor de sangue, é cor de morte, é cor de farsa/ É todo o sangue derramado nesses 500 anos [...] (Z'ÁFRICA BRASIL, 2002).

O tom de revolta é bastante visível na letra, mas também tematiza o protesto e a luta. É a demonstração da consciência dos fatos por parte dos que tiveram sua liberdade roubada, sua vida e força de trabalho exploradas, mas que agora buscam por mudanças e afirmação de sua identidade como povo digno, merecedor e feliz:

Luta, resistência, traçar a vida são batalhas [...] Porque sou índio, por que sou negro/Por isso sou feliz/ Por ter esse sangue correndo nas veias/ Por ter nascido de três raças formada brasileira/ habitada por índios, construída por negros/ Administrada por brancos/ Era nobreza ser herdeiro/ Era, era nada, era uma bandeira de gangues/ Falta o vermelho derramado por eles/ O vermelho do sangue (Z'ÁFRICA BRASIL, 2002).

$\mathrm{Na}$ primeira estrofe escrita em $3^{\mathrm{a}}$ pessoa, o rapper mantém certo distanciamento 
ao abordar os fatos universalmente, como "verdades" a serem contestadas, mas na $2^{\mathrm{a}}$ estrofe em diante assume-se como alguém que sente na pele todo drama que relata e marca seu pertencimento, sem lamento, ao dizer: Porque sou índio/porque sou negro/porque sou feliz.

Quanto à linguagem, aproxima-se da oralidade, do uso informal, com termos considerados "próprios" do universo do rap, o que não gera "pobreza"; pelo contrário, pode ser um recurso sofisticado ou inovador em termos poético-linguísticos, como se percebe no uso das metáforas, capazes de criar imagens surpreendentes:

E ali estava ela, hasteada/ para que todos pudessem ver as suas cores gradiantes/ Simbolizando ordem e progresso/ E aos redores grandes quilombos periféricos/ Um lugar de guerreiros, cujo olhar vermelho/ É pela liberdade entre terras e mares [...] Eles afogarão nesse sangue/ A cor que falta na bandeira brasileira" (Z’ÁFRICA BRASIL, 2002).

No final da música, aparece uma tentativa de "prestação de contas", embora de forma espiritual, porém sem benevolência, cobrando do colonizador/explorador a responsabilidade dos atos praticados, porque não haverá mais rendição:

Se existiu/ O julgamento final não foi divulgado/ É como sempre nesse país estar certo ou errado/E se os assassinos serão julgados por Deus na mesma maneira/ Eles afogarão nesse sangue/ A cor que falta na bandeira brasileira (Z'ÁFRICA BRASIL, 2002).

Em sala de aula, antes de se explorar questões relativas à letra propriamente dita, convém propor que os alunos pesquisem a origem do gênero poético/musical rap, para que o compreendam com porta-voz de reivindicações relacionadas à justiça, liberdade, identidade, condições precárias de vida, criminalidade e preconceito.

Então, com a compreensão acima já realizada, podem-se explorar certos aspectos da letra para que o aluno perceba sua profundidade. Primeiramente, a pesquisa do contexto de produção: quem é o autor/rapper, quando a escreveu (fato relevante: época próxima à comemoração de 500 anos do Brasil), para quem e onde foi veiculada (na grande mídia? Por que não?), pois essas questões já direcionam para a característica contestatória do rap.

Em seguida, pode-se partir para etapas de compreensão da letra, solicitando ao aluno listar os motivos que levam o rapper a propor que se insira a cor vermelha na bandeira brasileira e identificar a intertextualidade com outros textos - no caso o Hino Nacional. Uma análise da linguagem utilizada, as rimas, os efeitos de ironia, as metáforas e os efeitos de sentido que despertam no leitor/ouvinte também é importante que seja proposta ao aluno.

A situação atual do indígena no Brasil não pode deixar de ser abordada. Os conflitos atuais pela posse da terra com os grandes latifundiários, a população cada vez mais reduzida e outras questões devem ser pesquisadas e debatidas.

Como proposta de produção de texto, individual ou em duplas, os alunos podem 
escrever outra estrofe final para o rap, mantendo a coerência de linguagem e do tema. Para finalizar as atividades, uma proposta interessante é que redesenhem a bandeira brasileira de modo a demonstrar a reivindicação/denúncia do rapper. Mesmo sendo uma atividade simbólica, serviria para tornar a contestação mais palpável, bem como para que os alunos se utilizassem de diferentes linguagens para expor suas ideias.

Melô da Propaganda, do extinto grupo Quinto Andar, é a segunda música a ser analisada. Faz parte do álbum Piratão (2005), o único lançado em estúdio pelo grupo, pois os outros foram produções livres. Esse álbum pertence à terceira fase do rap nacional, uma vez que discute e ironiza questões da nossa sociedade movida pelo dinheiro e pelo consumo. Também analisa o sentimento de exclusão social que esse aspecto causa nas pessoas. A linguagem é mais irônica e menos ácida. Com ironia e certa "malandragem", comuns a essa fase, apresenta a crítica social:

Onde quer que eu vá, eu vejo... propaganda/ Do lado de fora dos prédios tem... propaganda/ No caminhão de lixo eu vejo... propaganda / Cê tá cercado!/ Mãos ao alto, ou melhor, no bolso/ Isso é um assalto e não é ICMS, mas o que ouço 24 $\mathrm{h}$ por dia/, privatizaram meu sonho sem descanso no sono, não tem espaço/ Onde ponho minha cabeça pra dormir, tá estampado o logo da Shell/ E até na praia eu vejo aviõezinhos da Vivo no céu / a natureza é trocada por outdoor e não podia ser melhor/ assim eu vejo Gisele Bündchen com vestido Dior [...] ( DEXTER, 2005).

As marcas famosas como Coca-Cola e personalidades importantes como Ronaldinho e Hebe são apontados de forma debochada e irônica, sem reverência àquilo que representam econômica ou socialmente. $O$ mundo das aparências, de falsas felicidades é questionado, não se esquecendo de citar preconceitos velados muito presentes na mídia, principalmente nas campanhas publicitárias, como se percebe no trecho abaixo:

A Coca me ligou, convidou pra fazer propaganda/ chamando um amigo que não podia ser gordo ou preto igual em Uganda / estranho, a bebida engorda, e é preta igual carvão/ qual o problema dum preto representá-la então?/ Casas Bahia, primeiro cheque pré/ depois nome no SPC, que só aumenta seu CC/ não abre conta no $\mathrm{BC}$,/ tá marcado igual $\mathrm{PC} /$ mas se eles que roubam você, então você entra num PC/[...] Quando ouço LS Jack eu vejo... propaganda/ O sorriso do Gugu me remete a... propaganda / A falsidade da Hebe é igual a ... propaganda / $\mathrm{Na}$ televisão quem manda?... Propaganda / Onde quer que eu vá eu vejo.... Propaganda / Do lado de fora dos prédios tem... propaganda (DEXTER, 2005).

Essa letra demonstra que o jovem rapper percebe as contradições do mundo que o rodeia, a manipulação das massas pela mídia e tenta "abrir os olhos" dos outros através de sua canção. É importante debater com o aluno as prioridades de uma sociedade que propagandeia o consumo de bens materiais como uma "necessidade" primordial ao mesmo tempo em que aceita a exclusão de acesso a esses bens por grande parcela da população: com a carência de muitos, garante-se a fartura de poucos. 
Em sala de aula, o debate sobre o assunto pode ser ampliado para leitura de outros textos, como por exemplo, Eu etiqueta, de Carlos Drummond de Andrade, um cânone da literatura brasileira, que, há várias décadas, já abordava, de forma poética, a "coisificação" do indivíduo manipulado pela propaganda e pelo consumo. Outras linguagens - charges, cartoons, HQs etc. - também podem ser utilizadas para enriquecer as análises.

\section{CONSIDERAÇÕES FINAIS}

Optar em tomar letras do rap nacional como motivo gerador de atividades em sala de aula é algo, até o momento, inovador. Este gênero poético/musical está fora do cânone atual e ainda bastante ausente nos livros didáticos, salvo raras exceções. Todavia, como foi argumentado, tem muito a contribuir para auxiliar o trabalho relacionado à leitura, escrita e reflexão crítica dos problemas socioeconômicos e culturais que nos afetam - e aos nossos alunos.

Enfim, é nisso que deve consistir o trabalho do professor: fornecer condições para que o aluno questione, reflita, denuncie, busque respostas aos seus anseios. Em outros termos, o trabalho em sala de aula deve servir para se refletir sobre a ideologia dominante, muitas vezes escamoteada em discursos de igualdade e democracia.

A voz dos rappers pretende romper o silêncio sobre os problemas enfrentados pelos jovens que estão nas ruas, mas também nos bancos de nossas escolas. A proposta é ouvir essa voz, vencer estereótipos e levar para dentro dos muros escolares essa manifestação artística que muito diz à/da vida do nosso aluno. Um salve para todos que acreditam nessa proposta!

\section{REFERÊNCIAS}

ADORNO, T. Educação e emancipação. São Paulo: Paz \& Terra, 1995.

ADORNO, T. Teoria da Semicultura. Revista Educação e Sociedade, Campinas, n. 56, ano XVII, p. 388-411, dez. 1996.

ADORNO, T.; HORKHEIMER, M. Dialética do Esclarecimento. Rio de janeiro: Jorge Zahar, 1985

ALMEIDA, F. Q.; GOMES, I. M.; BRACHT, V. Bauman \& a Educação. Belo Horizonte: Autêntica Editora, 2009.

BAKHTIN, M. Estética da criação verbal. 4. ed. São Paulo: Martins Fontes, 2003.

BARTHES, R. Aula. Tradução e posfácio de Leyla Perrone-Moisés. 10. ed. São Paulo: Cultrix, 2007.

BAUMAN, Z. Modernidade Liquida. Rio de Janeiro: Jorge Zahar, 2001.

BORTONI-RICARDO, S. M. Nós cheguemu na escola, e agora? São Pulo: Parábola Editorial, 2005.

BOSI, A. Cultura Brasileira e Culturas Brasileiras. In: BOSI, A. Dialética da colonização. São Paulo: Companhia das Letras, 1992.

BOSI, A. Narrativa e resistência. Itinerários, Araquara, n. 10, 1996. 
CHARTIER, R. A ordem dos livros: leitores, autores e bibliotecas na Europa entre os séculos XIV e XVIII. Brasília: Editora UNB, 1994.

CONTIER, A. D. O rap brasileiro e os Racionais MC's. In: Simpósio Internacional do Adolescente, 1, 2005, São Paulo. Disponível em: http://www.prodedings.scielo.br/scielo.php?scriptsci_artex\&.pid=MSC0000000008200 $500010001 \& n m=a b n$. Acesso em: 05 jul. 2015.

CUTI (Luiz Silva). Literatura negro-brasileira. São Paulo: Selo Negro, 2010.

DIAS, E. F. Leitura e poder. Universidade e sociedade. Ano V, n. 9, p. 67-70, out. 1995.

DUARTE, E. A. Por um conceito de literatura afro-brasileira. Ressegna iberistica, v. 37, n. 102, dez. 2014.

DUARTE, G. R. A arte na (da) periferia: sobre... vivências. In: ANDRADE, E. N. (Org.) Rap e educação, rap é educação. São Paulo: Summus, 1999.

EVARISTO, C. Da grafia desenho de minha mãe, um dos lugares de nascimento de minha escrita. In: ALEXANDRE, M. A. (org.). Representações performáticas brasileiras: Teorias, práticas e suas interfaces. Belo Horizonte: Mazza Edições, 2007.

FLEURI, R. M. Intercultura e educação. Educação, sociedade e cultura, n. 23, p. 91-124, 2005.

FONSECA, A. S. A. Versos violentamente pacíficos: o rap no currículo escolar. 2011. 242 f. Tese (Doutorado em Linguística Aplicada) - Instituto de Estudos da Linguagem, Universidade Estadual de Campinas, Campinas, 2011.

FOUCAULT, M. Vigiar e Punir nascimento da prisão. 20. ed. Tradução de Raquel Ramalhete. Petrópolis: Vozes, 1999.

FREIRE, P. A importância do ato de ler: em 3 artigos que se completam. 46. ed. São Paulo: Cortez, 1988.

FREIRE, P. Ação cultural para a liberdade. Rio de Janeiro: Paz e Terra, 1984.

GNERRE, M. Linguagem, escrita e poder. 3. ed. São Paulo: Martins Fontes, 1994.

GUIMARÃES, M. E. A. Rap: transpondo as fronteiras da periferia. In: ANDRADE, E. N. (Org.) Rap e educação, rap é educação. São Paulo: Summus, 1999.

LAJOLO, M. Do mundo da leitura para a leitura do mundo. São Paulo: Ática, 1997.

LAJOLO, M; ZILBERMAN, R. Literatura Infantil brasileira: História e Histórias. 6. ed. São Paulo: Ática, 1999.

MAAR, W. L. Adorno, Semiformação e Educação. Educação e Sociedade, Campinas, v. 24, n. 83, p. 459-476, ago. 2003.

MARRA, C. A. S. Violência escolar: a percepção dos atores escolares e a repercussão no cotidiano da escola. São Paulo: Annablume, 2007.

ORLANDI, E. P. Discurso e leitura. Campinas: Cortez, 1988.

POMPÉIA, R. O Ateneu. São Paulo: Scipione, 1995.

PROENÇA FILHO, D. A trajetória do negro na literatura brasileira. Estud. av., São Paulo, v. 18, n. 50, 2004.

ROJO, R. H. Letramentos múltiplos, escola e inclusão social. São Paulo: Parábola, 2009.

SILVA, F. C. T. Jovens, indignados e rebeldes: uma abordagem comparativa. In: MAYNARD, D. C. S.; MAYNARD, A. S. C. (org.). Visões do Mundo Contemporâneo. v. 2. LP-Books, 2013, p.17-48. 


\section{$\log$

SILVA, A. L. Música rap: narrativa dos jovens da periferia de Teresina - PI. Imaginário - USP, 2006, v. 12, n. 13, p. 83-112

SILVA, E. T. A Produção da Leitura na Escola. São Paulo: Ática, 2005.

SILVA, J. C. G. Arte e Educação: A experiência do movimento hip hop paulistano. In: ANDRADE, E. N. (org.) Rap e educação, rap é educação. São Paulo: Summus, 1999.

SOARES, Magda. As condições sociais da leitura: uma reflexão em contraponto. In: ZILBERMAN, R.; SILVA, E. T. (org.). Leitura: Perspectivas interdisciplinares. 5. ed. São Paulo: Ática, 2005.

SOARES, M. Letramento: Um tema em 3 gêneros. 2. ed. Belo Horizonte: Autêntica, 2001.

ZILBERMAN, R.; MAGALHÃES, L. C. Literatura infantil: autoritarismo e emancipação. São Paulo: Ática, 1982.

ZILBERMAN, R. (org.). A produção cultural para crianças. Porto Alegre: Mercado Aberto, 1982.

Recebido em: 15/09/2019

Aprovado em: 07/11/2019

Publicado em: 19/12/2019 